\title{
Tragicidade Contemporânea: uma análise sobre as possibilidades da tragédia no teatro contemporâneo
}

\author{
Nicole Alcebíades de Oliveira ${ }^{1}$
}

\section{Resumo}

Este projeto tem como objetivo investigar a possibilidade de uma retomada da tragédia no teatro contemporâneo, procurando compreender de que forma esse trágico se configuraria.

Palavras-chave: teatro contemporâneo, teoria do teatro, tragédia.

\section{Abstract}

This project aims to investigate the possibility of a resumption of tragedy in the contemporary theater, trying to understand how this tragedy would be configured.

Keywords: contemporary theater, theater theory, tragedy.

\section{Resumen}

Este proyecto tiene como objetivo investigar la posibilidad de una reanudación de la tragedia en el teatro contemporáneo, tratando de entender cómo se configura esta tragedia.

Palabras clave: teatro contemporáneo, teoría del teatro, tragedia.

\section{Textu Sacro}

\section{Relações possíveis entre a violência e o surgimento da dramaturgia grega}

Quando nos deparamos com o pequeno conjunto de tragédias gregas que sobreviveram desde o início do século $\mathrm{V}$ a.C. até a contemporaneidade, podemos verificar um padrão formal de escrita que, salvo as diferenças estilísticas entre os autores, parece convergir para uma única origem cultural. A partir de análises posteriores realizadas por inúmeros filósofos e teóricos, não podemos dizer que haja um consenso em relação ao que haveria de fundamental para compor uma tragédia, mas, de um modo geral, diversos estudos procuram compreender as implicações de sua forma e qual

\footnotetext{
1 Mestranda no PPGAC USP na área de Teoria e Prática do Teatro sob a orientação de Luiz Fernando Ramos. A pesquisadora atua como dramaturga no Coletivo [ph2]-estado de teatro, como professora de Artes no Ensino Fundamental e como monitora nas aulas de Metodologia das Artes Cênicas ministradas pela Profa. Dra. Maria Lúcia Pupo, na graduação em Artes Cênicas da USP.
} 
a necessidade grega de encenar um mito sagrado. $O$ que haveria nessa combinação entre forma trágica e mitologia que fez com que ela se configurasse exatamente dessa maneira que conhecemos?

Um desses pesquisadores, o antropólogo e crítico literário francês René Girard (1990), consegue vislumbrar na tragédia um mecanismo recorrente que, segundo ele, estaria presente no modo de conduta social de todos os povos antigos: o mecanismo expiatório. Esse mecanismo poderia explicar alguns comportamentos coletivos dessas civilizações, bem como possibilitar a compreensão do mito grego e da necessidade de transformá-lo em tragédia.

Segundo Girard, o que seria comum a todas as relações sociais humanas é o surgimento de uma violência entre homens, que ele chamará de violência fundadora. E o motivo para tal violência seria sempre o desejo mimético. Para ele, os homens não desejam os objetos simplesmente porque se interessam por ele, mas sim porque inconscientemente admiram o possuidor desse objeto. $\mathrm{Na}$ verdade, os homens disputam não para ter algo, mas para se assemelhar a determinado modelo. Nessa perspectiva, surgem os rivais:

O sujeito espera que este outro diga-lhe o que é necessário desejar para adquirir este ser. Se o modelo, aparentemente já dotado de um ser superior deseja algo, só pode se tratar de um objeto capaz de conferir uma plenitude ainda mais total. Não é por meio de palavras, mas de seu próprio desejo que o modelo designa ao sujeito o objeto sumamente desejável. (GIRARD, 1990, p.184)

A partir do momento em que essa rivalidade se aflora e que um homem passa a desejar estar no lugar do outro (para possuir seus bens, seus familiares etc.), os rivais simbolicamente passam a disputar um mesmo lugar social e encontram-se em um patamar de igualdade naquela situação:

Encontramos, tanto na religião primitiva quanto na tragédia, um mesmo princípio em funcionamento, sempre implícito, mas fundamental. A ordem, a paz e a fecundidade baseiam-se nas diferenças culturais. Não são as diferenças, mas sim o seu desaparecimento que provoca a rivalidade demente, a luta extrema entre os homens de uma mesma família ou de uma mesma sociedade. (GIRARD, 1990, p.68)

Essa rivalidade, ao despertar a violência de um terceiro, irá gerar um ciclo maior de violência generalizada, motivada por vinganças e acertos de contas entre os outros membros da sociedade. E esse processo poderia ser desastroso, levando uma tribo ao total desaparecimento. 
É justamente nesse contexto que intuitivamente e inconscientemente as civilizações criariam um mecanismo que daria conta de cessar o ciclo de violência e trazer de volta a paz: o mecanismo expiatório. Segundo Girard, ao se depararem com uma violência generalizada que se espalha de modo progressivo, os homens tendem a escoIher alguém como culpado por todo esse processo e a morte ou exílio dessa figura seria responsável pelo retorno da paz àquela população. Essa figura seria o bode expiatório.

De modo mais claro, o processo consiste em atribuir a culpa por todo mal que contamina aquela sociedade a alguém ao acaso e, com a imolação dessa vítima, livrar a todos da situação de violência a qual estão inseridas.

\begin{abstract}
Ali onde, alguns instantes antes, havia mil conflitos particulares, mil pares de irmãos inimigos isolados uns dos outros, novamente existe uma comunidade completamente una no ódio que lhe é inspirado por um só de seus membros. Todos os rancores disseminados em mil indivíduos diferentes e todos os ódios divergentes vão convergir, de agora em diante, para um indivíduo único, a vítima expiatória. (GIRARD, 1990, p.105)
\end{abstract}

Esse mecanismo implica em várias consequências. Primeiramente, passa a existir dois tipos de violência entre os homens: uma violência maléfica, que precisa ser combatida para não destruir tudo que a rodeia, e uma violência benéfica, realizada por todos contra a vítima e capaz de purificar a civilização do mal. Além disso, para que esse mecanismo não seja questionado e seu funcionamento seja perfeito, é preciso justificá-lo de alguma maneira, o que traz a necessidade de criar a religião e associar esse processo ao desejo dos deuses, como um modo de atribuir a outros a necessidade de matar. E, por fim, isso tudo gera a ideia de sagrado, que, ao contrário do atual senso comum, seria algo maléfico e benéfico ao mesmo tempo, justamente por ser capaz de purificar; mas para isso, é necessário usar, contraditoriamente, uma similar violência.

Girard utiliza esse mecanismo e suas variações para compreender a constituição das mais variadas sociedades e nem uma delas parece fugir à regra, com ênfase na sociedade grega. Segundo o teórico, algumas civilizações acabaram por instituir essa figura periodicamente, antes mesmo que a crise aparecesse, para evitar a violência antes até que ela fosse gerada. Essa seria a explicação para o phamakós ${ }^{2}$ grego e para o homo saccer ${ }^{3}$ romano.

O modo de escolha da vítima era algo problemático, pois ao mesmo tempo em que era arbitrário acabava por justificar-se de alguma maneira. Não poderia ser alguém

\footnotetext{
2 Pharmakós: Figura escolhida arbitrariamente para ser torturada ou exilada periodicamente na Grécia.

3 Homo Saccer: do latim "homem sagrado". Figura ambígua da sociedade romana que, ao mesmo tempo, era vista como maléfica e pura. Não era digno de ser sacrificado, mas poderia ser morto sem que isso acarretasse consequências para o assassino
} 
importante cuja morte geraria ainda mais conflito, o que levava geralmente a escolha por figuras marginais da sociedade. Mas, em alguns casos, poderia ser alguém crucial para o sistema daquela civilização, como um rei ou figuras religiosas, o que levaria a uma mudança real na ordem vigente.

É necessário esclarecer que a vítima expiatória, ainda que vista como vítima por nós contemporâneos, precisava ser vista como culpada para que o mecanismo tivesse efeito. Por isso, a sua escolha estava associada a alguma acusação, na qual a vítima poderia inclusive ter feito algum mal (algumas vezes sem intenção) e, em alguns casos, antes de ser imolada, ela era obrigada a realizar algo de natureza impura para só então Ihe atribuírem a culpa. Isso explicaria situações em que a vítima era obrigada a cometer incesto, promiscuidades ou algum outro tipo de transgressão para depois se tornar culpada e morta.

Ainda como derivado desse mecanismo, Girard explica a constituição do sacrifício, que nada mais seria do que um modo simbólico de substituição da vítima expiatória. Ao invés de matar alguém importante, podemos substituir simbolicamente por alguém de menor relevância, e posteriormente, até por animais. Aí estaria o início da tragédia, segundo o autor. Quando o ser humano é capaz de lidar com a violência que o cerca de maneira simbólica, o sacrifício, o ritual e o mito se solidificam: "A elaboração mítica é um processo não consciente fundado sobre a vítima expiatória e que tem como preço a verdade da violência; esta verdade não é recalcada, mas desligada do homem e divinizada" (GIRARD, 1990, p.173).

Portanto, o mecanismo expiatório foi a forma antiga encontrada para concentrar as forças que regem uma violência generalizada em um único indivíduo, justificando essa atitude como o desejo divino, e, assim, criando a religião. Quando esse processo se transforma em sacrifício, a culpa é atribuída a alguém simbólico, o que criaria a capacidade humana de pensar simbolicamente e assim, o surgimento da cultura entre os homens. Dessa união entre o sagrado e o sacrifício, algumas manifestações culturais se consolidariam e, na Grécia, seria o início da tragédia. São elas: a festa e o ritual.

$\mathrm{Na}$ festa antiga, os homens agrupavam-se para cometer atos de transgressão por determinado período. Atos que colocariam toda a sociedade em situação de igualdade social e possibilitariam uma violência generalizada. Era uma situação de caos, na qual incestos, uso excessivo de álcool, promiscuidade, entre outros atos, passam a ser completamente permitidos. É quase como se a festa propusesse um período 
de retomada da violência generalizada de modo libertador. Após a festa, uma vítima sacrificial seria imolada e deveria ser a morte de toda aquela situação, também de modo simbólico, e o retorno da paz e das regras.

O ritual, por sua vez, tem a mesma função da festa: representar a crise que deu início a tudo. Aqui, não se poderão transgredir todas as regras, mas a ideia é repetir periodicamente de modo simbólico a violência fundadora que deu origem ao mecanismo e acabar por sacrificar alguém, permitindo que "os deuses" devolvam a paz. Por isso, era comum nos rituais do período encenar momentos de violência entre rivais, coreografar atos de ofensa à vítima, e até sacrificar aquilo que representasse o mal social e o patamar obscuro de igualdade em que todos se encontram, o duplo monstruoso, daí a escolha de muitos povos por sacrificar irmãos gêmeos, por exemplo.

Não é de se estranhar que as festas eram sempre ligadas à religiosidade e os rituais eram também momentos festivos nessa época. Ambos seriam esferas da mesma coisa.

\begin{abstract}
Se a crise das diferenças e a violência recíproca podem ser objeto de uma comemoração alegre, é por se mostrarem como o antecedente obrigatório da resolução catártica que as concluem. O caráter benéfico da unanimidade coletiva fundadora tende a retroceder para o passado, avivando cada vez mais os aspectos benéficos da crise, que tem então seu sentido invertido. A indiferenciação violenta adquire a conotação favorável que fará dela, no final das contas, o que chamamos de festa. (GIRARD, 1990, p.154)
\end{abstract}

Os mitos, outro elemento importante em todas essas culturas, deveriam servir para contar situações em que a sociedade viveu uma violência generalizada e se curou à custa de uma vítima. Essa vítima pode ser tanto um bode expiatório quanto uma vítima sacrificial. Mas ao invés de fazer isso de modo generalizado, ele concentra a violência em algumas poucas personagens que devem simbolizar o todo.

Ao observar a trama do mito, podemos verificar o quanto se complexifica o pensamento simbólico da sociedade, na medida em que novos símbolos são encontrados para explicar o período de violência e o mecanismo expiatório: a violência generalizada pode constituir-se como uma peste ou maldição divina; os rivais, iguais em seu desejo, podem ser simbolizados por irmãos ou parentes de sangue etc. Há um refinamento do processo de construção simbólica.

E como forma mais complexa de encenar esse processo, e provavelmente por desgaste das formas anteriores ${ }^{4}$, surge a tragédia grega, que daria conta de unir o

4 René Girard aponta que, ao substituir o mecanismo expiatório pelo sacrifício, este último acaba por se repetir antes mesmo que a violência aconteça, gerando um desgaste no ritual. A esse desgaste causado pelo 
caráter festivo, a dimensão ritualística e a mitologia em um único evento: os festivais teatrais. A tragédia grega, enquanto forma de arte, teria de ser capaz de recontar o mito e conseguir provocar nos espectadores a sensação de participar como observadores da violência e vislumbrar sua purificação final. Essa seria a necessidade da catarse, e não ter qualquer função de natureza moralizante.

Como a festa e todos os outros ritos, a tragédia grega é inicialmente apenas uma representação da crise sacrificial e da violência fundadora. [...] As máscaras desaparecem quando os monstros tornam-se novamente homens, quando a tragédia esquece completamente suas origens rituais, o que certamente não quer dizer que ela tenha deixado de desempenhar um papel sacrificial no sentido amplo do termo. Pelo contrário, ela substituiu completamente o rito. (GIRARD, 1990, p.210)

Mas para que a tragédia tenha essa função, não é somente a trama mitológica que precisa estar presente, mas torna-se necessário encontrar formas de contar essa história que deem conta dos seus objetivos. Nascem aí as bases da dramaturgia grega que viriam a ser a base da dramaturgia ocidental. Alguns elementos formais criados na Grécia para satisfazer a necessidade de mostrar essa crise são elementos presentes em textos teatrais até os dias de hoje. Como exemplo, podemos falar sobre dois aspectos do texto trágico ateniense: os elementos simétricos e as alternâncias.

Os elementos simétricos, como o próprio nome anuncia, são os elementos do texto que representam os duplos monstruosos que são as personagens umas das outras. São figuras "espelho" de outras figuras que evidenciam o desejo mimético que envolve aquele princípio de violência. É maneira do dramaturgo mostrar que as figuras que rivalizam são iguais em seu caráter e desejo:

Caso fosse necessário definir a arte trágica em uma única frase, uma só característica deveria ser mencionada: a oposição de elementos simétricos. Não há qualquer elemento do enredo, da forma ou da linguagem trágica que esta simetria não desempenhe um papel essencial. (GIRARD, 1990, p.61)

Já as alternâncias são a maneira do dramaturgo mostrar que, ainda que de modo geral todos estejam em oposição, não há ninguém que esteja certo ou errado o tempo todo, de modo que a decisão por aquele que será a vítima acabe por ser arbitrária. Para isso, aquele que inicia como o grande poderá terminar a peça como o bode expiatório e aquele que não é escutado no início poderia ser o único a ter razão. Portanto, durante todo o enredo, a razão parece alternar entre as personagens-rivais

distanciamento do sacrifício da necessidade de sua origem, ele dá o nome de "crise sacrificial". Esta crise muitas vezes fazia com que a violência viesse à tona e se voltasse ao início do processo expiatório. Mas ela também gerou a necessidade de encontrar novas formas de "prevenção" da violência, como a tragédia. 
de modo que o público acompanhe todo o processo de violência estre elas através das falas em oposição.

Esses elementos formais, atrelados aos elementos simbólicos da trama, sobreviverão ao fim da tragédia grega influenciando dramaturgos posteriores, que, na grande maioria das vezes, nem sequer compreendiam a origem dessa estrutura. Um dos dramaturgos que, segundo Girard, entende isso de alguma forma e passa a utilizar essa maneira de escrita é William Shakespeare, que desenvolve seus textos a partir do mecanismo expiatório ${ }^{5}$.

Mas a estrutura dramatúrgica está tão atrelada a esse processo que mesmo dramaturgos contemporâneos com experiências textuais distantes da trama mitológica acabam ainda por ter alguma ligação com essa estrutura. Trago aqui dois exemplos que ilustram essa questão.

O primeiro é o texto Horácio do dramaturgo alemão Heiner Müller. Esse texto, inspirado em uma obra de sua admiração escrita por Bertolt Brecht, conta a história de uma guerra entre duas cidades: Roma e Alba. Mas ao invés dos exércitos se enfrentarem, foi escolhido um homem de cada cidade para lutar, de modo que Horácio lutaria por Roma e Curiácio lutaria por Alba. No entanto, Curiácio era noivo da irmã de Horácio e, ao matá-lo, Horácio desperta a tristeza profunda de sua irmã, que o recebe em lágrimas. O herói se sente ofendido, pois acredita que a irmã deveria amar antes a Roma do que a um homem e acaba por matá-la também. O povo romano encontra-se em um novo impasse: Horácio deve ser exaltado como herói de Roma ou deve ser condenado por ser o assassino de sua irmã?

A trama, extremamente semelhante à estrutura mitológica, chama atenção por diversos elementos. Primeiramente, dois homens substituem a briga entre seus povos, o que é o mesmo que atribuir a alguns personagens a violência generalizada, sendo este o princípio fundamental do mito. Quando um desses homens triunfa sobre o outro e depois assassina a sua irmã, ele se torna um ser maléfico e benéfico para a cidade ao mesmo tempo, o que era o caráter fundamental do sagrado e, portanto, do bode expiatório. Assim, ainda que coroado, Horácio acaba sendo morto pelo seu povo.

Mas, para além da trama, a estrutura do texto de Heiner Müller nos chama mais ainda atenção. Ele leva ao extremo as alternâncias e os elementos simétricos, desenvolvendo toda a sua escrita sobre essa forma:

5 Sobre isso, Girard escreveu o livro A theater of envy: William Shakespeare. New York: Oxford University Press, 1991. 
E um dos romanos gritou:

Ele venceu. Roma reina sobre Alba.

E um outro romano respondeu:

Ele matou a sua irmã.

E os romanos gritaram uns contra os outros:

Honrem o vencedor

Executem o assassino

E romanos empunharam a espada contra romanos na luta

Se como vencedor deveria ser honrado

Ou julgado como assassino Horácio. (MÜLLER, 2003, p.125)

Também um aspecto referente à encenação é importante. $O$ autor, através da rubrica, explica que os atores serão "jogadores" durante a encenação, alternando seus papeis: "Quem disse o seu texto e jogou seu jogo, volta para a posição inicial, ou seja, troca de papel" (MÜLLER, 2003, p.131). Com isso, o autor busca, através da encenação, evidenciar o caráter generalizado da violência, tirando a culpa sobre o individuo e diluindo-a na esfera coletiva. É como se a encenação dissesse que o Horácio é apenas um símbolo e que sua conduta precisa ser pensada na esfera social. Além disso, esse caráter de jogo proposto pela encenação se aproxima muito das representações feitas pelos povos primitivos durante os rituais sacrificiais: todo o povo interpretava a situação da violência fundadora, revezando-se entre personagens que simbolicamente retomavam a crise.

Outro exemplo contemporâneo de semelhança com a estrutura trágica é o texto Na Solidão dos Campos de Algodão, de Bernard-Marie Koltés. Nesse caso, sem uma trama que fique exatamente clara ao leitor, o autor propõe um diálogo entre o Dealer ${ }^{6}$ e o Cliente, um homem qualquer que cruza seu caminho pela rua. $\mathrm{O}$ assunto que dispara o diálogo é passível de relacionar-se com a origem da violência entre os homens: o desejo por algo que o outro possa fornecer. Novamente, a trama possui alguma ligação com o mecanismo expiatório, mas isso aparece de modo atualizado para as possíveis relações comerciais contemporâneas:

\footnotetext{
Não que eu tenha adivinhado o que você possa desejar, nem que eu esteja apressado em conhecer; pois o desejo de um comprador é a coisa mais melancólica que existe, que se contempla como um pequeno segredo que pede apenas para ser revelado e que se toma um tempo antes de revela-lo; como um presente que se recebe embrulhado e que se toma um tempo desfazendo o laço. Mas é que eu mesmo desejei, desde o tempo em que estou nesse lugar, tudo o que todo homem ou animal pode desejar a esta hora escura, e que o faz sair de casa apesar dos grunhidos selvagens dos animais insatisfeitos e dos homens insatisfeitos; é por isso que eu sei, melhor que o comprador inquieto que guarda ainda por um tempo o seu mistério como uma pequena virgem educada para ser uma puta, que o que você vai me pedir eu já tenho, e que basta a você, sem que se sinta ferido pela aparente injustiça que há em ser o pedinte frente àquele que oferece, me fazer o pedido (KOLTÉS, 1995, p.91).
}

6 Espécie de fornecedor de algo possivelmente ilegal 
E mais uma vez, para além do conteúdo, é a própria forma que se revela feita de alternâncias e de elementos simétricos. Todo o texto é formado por um diálogo entre as duas figuras. E cada fala do diálogo desenvolve um longo pensamento em oposição ao outro, sendo então um grande diálogo de pequenos monólogos. Cada monólogo se desenvolve de maneira simétrica ao anterior, procurando fazer com que o leitor alterne a credibilidade que deposita em cada figura. O Dealer afirma o desejo do cliente de possuir algo que ele pode fornecer, e ele parece seguro o suficiente para acreditarmos nisso. Mas, na sequência, o Cliente nega qualquer tipo de desejo de transação comercial, de modo que também acreditamos que isso não ocorrerá. E o texto prossegue o tempo todo a partir dessas alternâncias.

O final é ainda mais intrigante se considerarmos que Koltés ignora o pensamento de Girard sobre o trágico. As figuras, que durante toda trama se colocaram como rivais, assumem sua posição de igualdade uma perante a outra, nos remetendo à teoria de que a violência emana de iguais, de duplos:

Bom, eu te ofereço a igualdade. Um casaco na poeira, eu pago com um casaco na poeira. Sejamos iguais, na igualdade do orgulho, na igualdade da impotência, igualmente desarmados, sofrendo igualmente do frio e do quente. A sua seminudez, a sua metade de humilhação, eu as pago com a metade das minhas (KOLTÉS, 1995, p.104).

E, por fim, ambas recusam a possibilidade de entrar em um conflito real e terminam tão desoladas quanto começaram.

É possível dizer que o que Koltés apresenta é um exemplo arquetípico de uma situação de violência fundadora que não se concretiza: primeiro, há o desejo mimético, mas que aqui é o tempo todo recusado; depois, há a igualdade entre as figuras, que aqui não gera rivalidade real; e, por último, haveria violência, mas as personagens preferem permanecer juntas num mundo que parece mais inseguro que o antigo. É como se o autor partisse inconscientemente do sistema de violência fundador para transformá-lo à luz do mundo contemporâneo, no qual, em meio a tanta individualidade e solidão, é melhor manter-se unido àquele que se opõe como uma maneira de estar menos só.

Essas duas peças talvez sejam suficientes para ilustrar o quanto ainda a dramaturgia contemporânea se mostra impregnada de conteúdos e formas trágicas, e o quanto isso pode significar que esta ainda é uma das maneiras mais eficazes do ser humano tentar compreender e recontar a violência: cenicamente. 
E daí nós podemos pensar o caráter sagrado do texto teatral: não porque ele é imprescindível para o teatro como fora um dia, mas porque consegue formalmente nos conectar com às bases iniciais do pensamento simbólico sobre a violência em nossa sociedade, e trazer formalmente à tona os mecanismos que regem o conflito entre os homens, conflitos esses de natureza ambígua, como a própria natureza humana parece ser.

\section{Bibliografia}

GIRARD, René. A Violência e o Sagrado. São Paulo: Paz e Terra, 1990.

KOLTÉS, Bernard-Marie. Na Solidão dos Campos de Algodão. In: PEIXOTO, Fernando (org.). O Teatro de Bernard-Marie Koltés. São Paulo: Hucitec, 1995.

MÜLLER, Heiner. Horácio. In KOUDELA, Ingrid. Heiner Müller: o espanto no teatro. São Paulo: Perspectiva, 2003. 